\section{Metabolic Recovery in \\ Caudate Nucleus of Children Following Cerebral Hemispherectomy}

Harry T. Chugani, MD, ${ }^{*}$ and Bob Jacobs, $\mathrm{PhD} \dagger$

In 3 children who had undergone cerebral hemispherectomy (hemidecortication) between the ages of 1 year 5 months and 4 years for the alleviation of intractable epilepsy, cerebral glucose utilization was studied serially with positron emission tomography. Three to 7 months after hemispherectomy, glucose utilization in the caudate nuclei on the side of hemispherectomy had decreased to below preoperative values, presumably due to total deprivation of ipsilateral cortical input. One to 2.5 years after surgery, complete restoration of glucose metabolic activity to preoperative levels was seen in 2 patients and partial recovery was seen in 1 patient. These alterations of cerebral glucose utilization are believed to reflect microscopic anatomical reorganizational changes (e.g., collateral sprouting) that have been documented following similar lesions in several animal models. Our findings suggest that positron emission tomography may provide a sensitive measure of developmental brain plasticity in vivo.

Chugani HT, Jacobs B. Metabolic recovery in caudate nucleus of children following cerebral hemispherectomy. Ann Neurol 1994;36:794-797

Immature vertebrates in many species can sustain damage to relatively large areas of the brain and yet show remarkably little functional deficit. This is generally attributed to the reorganizational potential of the developing brain $[1,2]$. The greater plasticity of the developing brain over the adult state is known as the Kennard effect, although evidence supporting this principle had been presented long before Kennard (reviewed in [3]).

Children who have undergone neurosurgical procedures, such as multilobar resection or hemispherectomy for the alleviation of intractable epilepsy, pro-

From the *Departments of Neurology, Pediatrics, and Radiology, Children's Hospital of Michigan and Wayne State University, Detroit, MI, and $\oplus$ Department of Psychology, The Colorado College, Colorado Springs, CO.

Received Nov 10, 1993, and in revised form Feb 16 and Apr 4, 1994. Accepted for publication Apr 21, 1994.

Address correspondence to Dr Chugani, Division of Pediatric Neurology and the PET Center, Children's Hospital of Michigan, 3901 Beaubien Boulevard, Detroit, MI 48201. vide a unique opportunity for studying developmental brain plasticity. These subjects manifest marked cognitive and motor sparing/recovery following surgical resection $[4-7]$. Skills such as language, visual processing, auditory-temporal processing, abstraction, and reasoning may be retained after hemispherectomy $[8$, 9]. Even the ability to perform complex tasks (e.g., interfield visual discrimination) has been reported in humans who underwent hemispherectomy during childhood [10].

We present here evidence of brain plasticity as indicated by alterations in the pattern of glucose consumption determined with $2\left[{ }^{18} \mathrm{~F}\right]$ fluoro-D-glucose (FDG) and positron emission tomography (PET) in 3 children who had undergone cerebral hemispherectomy in infancy or childhood.

\section{Materials and Methods}

The clinical features of the 3 patients included in this report and the circumstances leading to hemispherectomy are provided in the Table.

All studies were performed with informed consent and in accordance with the policies of the University of California at Los Angeles (UCLA) Human Subject Protection Committee. The FDG-PET procedure, as applied to infants and children, was discussed previously [11]. Briefly, the subjects were fasted for 4 hours prior to PET. A venous catheter was inserted into either a hand or a foot to administer FDG $(0.143$ $\mathrm{mCi} / \mathrm{kg}$ ). Just prior to, and for 30 minutes after FDG administration, sensory stimulation was minimized by dimming the lights and discouraging speech. Forty minutes after FDG injection, scanning of the brain was initiated using either the NeuroECAT positron tomograph (12 images, spatial resolution of $8.4 \mathrm{~mm}$ in plane of section, $12.4-\mathrm{mm}$ slice thickness) or the CTI 831 positron tomograph (15 images, spatial resolution of $5.6 \mathrm{~mm}$ in plane of section, 6.3 -mm slice thickness). A head holder was used to minimize movement during scanning, and all tomographic slices were obtained parallel to the canthomeatal plane. Absolute measurements of cerebral glucose metabolic rates were not obtained because of the increased invasiveness of this process, which requires arterial blood sampling in these children who had already benefited from surgery.

Preoperative and postoperative PET images were displayed on a computer monitor and analyzed initially by visual inspection. Subsequently, the concentrations of radioactivity in subcortical brain regions (basal ganglia and thalamus) spared by surgery were determined by drawing regions of interest, and expressed as ratios to the concentrations of the same brain regions in the contralateral (intact) cerebral hemisphere to yield indices of regional metabolic asymmetry for each PET study. An asymmetry index was chosen rather than normalization to the entire intact cerebral hemisphere (as is usually done in analyses of PET data) because glucose metabolic rates undergo complex and hitherto inadequately described changes during brain development [12], particularly in the cerebral cortex, thus precluding its use as a "stable" reference in longitudinal studies such as the present one. 


\begin{tabular}{|c|c|c|c|c|c|c|}
\hline $\begin{array}{l}\text { Subject No./ } \\
\text { Gender }\end{array}$ & Clinical Information & $\begin{array}{l}\text { Age at Hemispherectomy and } \\
\text { Outcome }\end{array}$ & Age at PET Scan & Thalamus ${ }^{2}$ & $\begin{array}{l}\text { Lenticular } \\
\text { Nuclei }^{a}\end{array}$ & Caudate $^{\mathrm{a}}$ \\
\hline $1 / \mathrm{M}$ & $\begin{array}{l}\text { Normal birth. Seizure onset at } \\
\text { age of } 8 \mathrm{hr} \text {; uncontrolled with } \\
\text { medication } \\
1 \mathrm{yr}, 6 \text { mo: developmental delay } \\
\text { (3-4 mo level); no speech; nor- } \\
\text { mal visual tracking; diffuse hy- } \\
\text { potonia; } \mathrm{R} \text { arm monoparesis; } \\
\text { reached for objects with } \mathrm{L} \\
\text { hand }\end{array}$ & $\begin{array}{l}1 \text { yr, } 6 \text { mo: L hemispherectomy. } \\
6 \text { yr: ambulatory; only occasional } \\
\text { seizure associated with febrile } \\
\text { illnesses; functions at about } 3 \text { - } \\
\text { yr-old level }\end{array}$ & $\begin{array}{l}\text { Pre: } 1 \mathrm{yr}, 3 \mathrm{mo} \\
\text { Post: } 2 \mathrm{yr} \\
\text { Post: } 4 \mathrm{yr}\end{array}$ & $\begin{array}{l}0.86 \\
0 \\
0\end{array}$ & $\begin{array}{l}0.88 \\
0 \\
0\end{array}$ & $\begin{array}{l}0.84 \\
0.66 \\
0.86\end{array}$ \\
\hline $2 / \mathrm{M}$ & $\begin{array}{l}\text { R hemimegalencephaly. Intracta- } \\
\text { ble epilepsy from } 2 \text { nd day of } \\
\text { life } \\
1 \text { yr, } 5 \text { mo: no language; did not } \\
\text { roll over; no visual regard; } \mathrm{L} \\
\text { hemiparesis }\end{array}$ & $\begin{array}{l}1 \text { yr, } 5 \text { mo: } R \text { hemispherectomy. } \\
3 \text { yr, } 5 \text { mo: acquired receptive } \\
\text { but not expressive language; } \\
\text { points to body parts; babbles, } \\
\text { plays with puzzles; L hemipare- } \\
\text { sis unchanged, no spasticity }\end{array}$ & $\begin{array}{l}\text { Pre: } 1 \mathrm{yr}, 4 \mathrm{mo} \\
\text { Post: } 2 \mathrm{yr} \\
\text { Post: } 2 \mathrm{yr}, 5 \mathrm{mo}\end{array}$ & $\begin{array}{l}0.92 \\
0 \\
0\end{array}$ & $\begin{array}{l}0.94 \\
0 \\
0\end{array}$ & $\begin{array}{l}1.13 \\
0.53 \\
0.69\end{array}$ \\
\hline $3 / F$ & $\begin{array}{l}\text { Difficult and prolonged labor; } \\
\text { perinatal anoxic-ischemic dam- } \\
\text { age; seizure onset on } 2 \text { nd, un- } \\
\text { controlled } \\
4 \text { yr: developmental delay; no } \\
\text { speech; poor head control; did } \\
\text { not crawl; R spastic hemipa- } \\
\text { resis }\end{array}$ & $\begin{array}{l}4 \text { yr: } \mathbf{L} \text { hemispherectomy } \\
9 \text { yr: ambulatory; seizure free; lan- } \\
\text { guage function at about } 6-7 \\
\text { yr; dysarthric; } R \text { visual field } \\
\text { deficit; can squeeze with } \mathrm{R} \\
\text { hand, flex elbow, elevate shoul- } \\
\text { der, but no fine motor control } \\
\text { of } \mathrm{R} \text { hand }\end{array}$ & $\begin{array}{l}\text { Pre: } 3 \mathrm{yr}, 11 \mathrm{mo} \\
\text { Post: } 4 \mathrm{yr}, 3 \mathrm{mo} \\
\text { Post: } 6 \mathrm{yr}, 1 \mathrm{mo}\end{array}$ & $\begin{array}{l}0.72 \\
0 \\
0\end{array}$ & $\begin{array}{l}0.90 \\
0 \\
0\end{array}$ & $\begin{array}{l}0.93 \\
0.51 \\
0.91\end{array}$ \\
\hline
\end{tabular}

${ }^{a}$ Normalized value represents structure ipsilateral to hemispherectomy/structure contralateral to hemispherectomy.

$\mathrm{L}=$ left; $\mathrm{R}=$ right.

\section{Results}

Ratios of metabolic asymmetry for the basal ganglia and thalamus are presented in the Table. In normally developing children, metabolic asymmetry is $\pm 8 \%$ for cerebral cortical and cerebellar structures, and $\pm 5 \%$ for basal ganglia and thalamus across subjects (unpublished data, 1987).

Metabolic changes suggestive of reorganization after hemispherectomy were seen in the caudate nucleus of all 3 parients. Three to 7 months after surgery, glucose utilization in the caudate ipsilateral to the hemispherectomy had decreased below preoperative values (see Table). Partial or complete restoration of glucose metabolic activity to preoperative levels in the affected caudate was observed in PET studies performed 1 to 2.5 years postoperatively. The recovery of caudate glucose utilization reached preoperative levels in Patients 1 and 3. In Patient 2, metabolic recovery in the caudate was less complete, possibly because this child's neurological condition (hemimegalencephaly) is believed to be associated with bilateral cerebral abnormalities [13], and hence, consists of neural substrate that cannot fully support reorganizational changes following surgery (see below). In contrast to findings in the caudate, the lenticular nuclei and the thalamus exhibited a total loss of glucose metabolic activity postoperatively, and no measurable recovery in subsequent PET studies (see Table, Fig).

\section{Discussion}

The ability of various species to compensate in response to brain injury is dependent on the maturational state of the nervous system at the time of injury. Developmental brain plasticity has been particularly well studied in the cat [14], in which neonatal focal ablation (e.g., of sensorimotor cortex) or cerebral hemispherectomy is associated with far better functional recovery (e.g., of postural reflexes and locomotion) than is a comparable adult lesion. Several anatomical reorganizational processes have been observed: (i) The intact sensorimotor cortex of kittens sustaining contralateral sensorimotor ablation retains exuberant projections present in normal neonatal animals, resulting in bilateral corticothalamic and corticorubral projections [14]; (ii) the intact corticospinal pathway in cats that underwent hemispherectomy as neonates reinnervates the partially deafferented thalamic, brainstem, and spinal cord nuclei with new collateral fibers to a much greater extent than in cats with lesions made during adult years [15]; and (iii) following hemispherectomy, there is less retrograde neuronal degeneration in the thalamus and upper brainstem nuclei of 


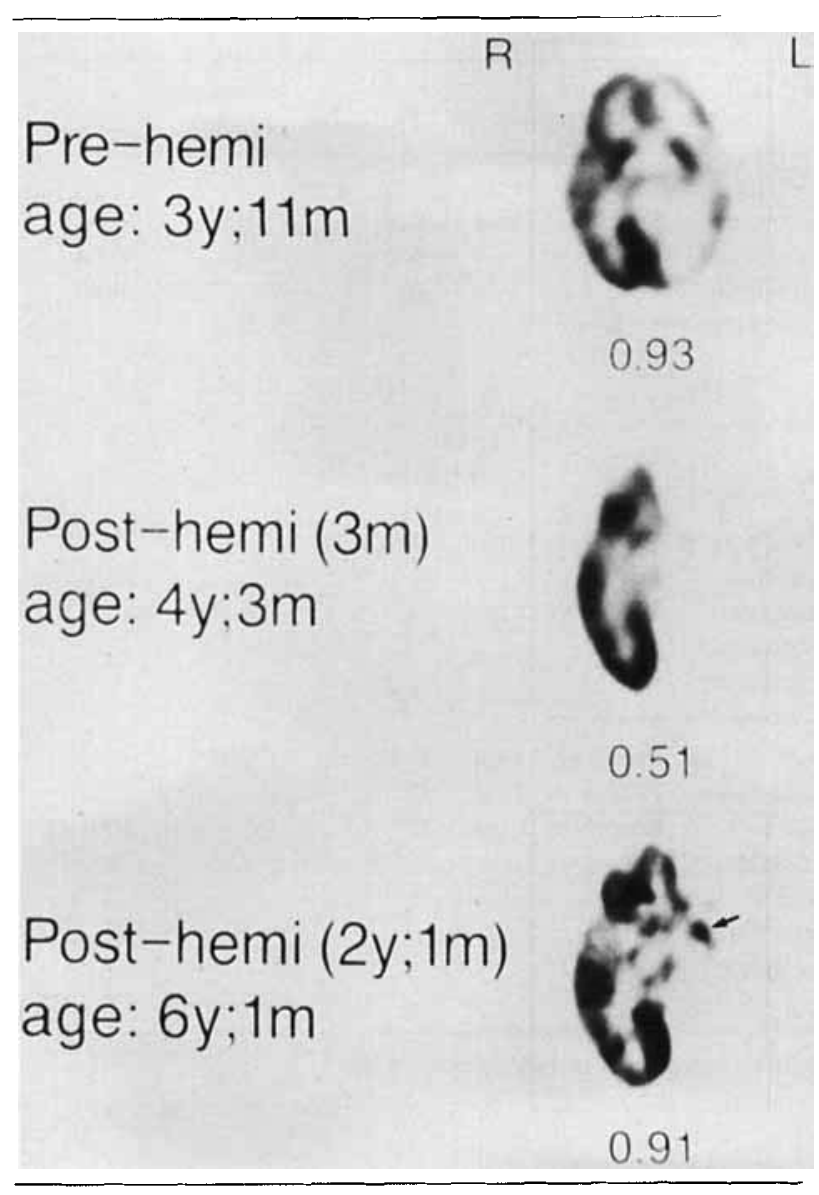

PET scan of cerebral glucose utilization in Patient 3. The numerical values are indices of asymmetry, and represent ratios of glucose metabolic rate in the caudate nucleus ipsilateral to bemispberectomy to the metabolic rate in the caudate contralateral to bemispherectomy. Metabolic recovery in the caudate nucleus postoperatively is indicated on the third PET image (arrow). The caudate with a ratio of 0.51 is not clearly visualized on the second PET image due to a scaling factor; that is, its metabolic rate is considerably less than the rates of several otber structures seen on this plane.

kittens than adults [16]. Preliminary data on kittens after hemispherectomy from our laboratory $[17]$ indicated that glucose utilization in brain regions (e.g., ventrolateral thalamus on hemispherectomy side) receiving collateral sprouting can be detected using a ${ }^{14} \mathrm{C}$-2-deoxyglucose (2DG) autoradiography technique.

Our findings in humans are relevant in light of previous studies in several species documenting plasticity of the caudate nucleus following injury. For example, 2DG autoradiographic studies in adult macaque monkeys subjected to unilateral ablation of Brodmann's areas 4 ad 6 demonstrated transient ipsilateral glucose hypometabolism in the caudate followed by a partial restoration of glucose utilization 8 weeks after ablation, presumably secondary to enhanced influence from unablated ipsilateral corticostriatal pathways [18].
This mechanism, however, cannot account for the metabolic recovery of the caudate in the present study (see Fig) because of the total disconnection of ipsilateral corticostriatal pathways. A more likely mechanism in these subjects is increased influence from crossed corticostriatal pathways. In the monkey, the caudate and putamen receive bilateral projections from motor cortex $[19]$, and following neonatal bilateral frontal cortical lesions, the caudate assumes functions (e.g., delayed response) mediated by dorsolateral prefrontal cortex [20]. In the rat, the striatum receives bilateral projections from all major areas of cerebral cortex, although ipsilateral projections predominate [21]. With neonatal (but not adult) rat hemispherectomy, crossed corticostriatal projections increase [22]. Behaviorally, in rat [23], sparing of contralateral motor function following neonatal motor cortex ablation is markedly diminished if the caudate-putamen is also removed. This also appears to be the case in humans [4]. Interestingly, none of the subjects in the present study had a return of glucose metabolic activity in the ipsilateral thalamus, despite the fact that in the monkey the dorsal thalamus receives contralateral projections from frontal association cortex [24].

The alterations of glucose utilization in the human caudate nucleus described in the present study presumably reflect progressive changes of energy demand associated with anatomical reorganization, such as those described in kittens after hemispherectomy [14, 15, 17]. Further evidence to support this notion comes from Sharp and Evans [25], who demonstrated that electrical stimulation of remaining motor cortex in $90-$ day-old rats following unilateral sensorimotor cortex removal elicited an increase of glucose utilization in ipsilateral basal ganglia and thalamus, and contralateral cerebellum if the lesion was made at 30 days, but bilateral increases in animals with lesions made at the age of 1 day. In humans, hemispherectomy is not performed for lesions acquired in adulthood. Recovery of glucose consumption in the caudate nucleus of our patients possibly could have resulted from a compensatory increase in physiological activity by remaining neural processes within this structure, or less likely, from persistence of increased glial activity in the chronic state. Finally, because our data are presented as asymmetry ratios and not absolute glucose metabolic rates, which are more difficult to achieve in children than in adults, it remains possible that decreased metabolic activity in the contralateral caudate or bilateral changes in the caudate could have contributed to our findings. These issues are currently being addressed in our laboratory.

We would like to thank Drs Charles Kennedy and Michael Phelps for critically reviewing this manuscript. 


\section{References}

1. Irle E. Lesion size and recovery of function: some new perspectives. Brain Res Rev 1987;12:307-320

2. Kolb B, Whishaw IQ. Plasticity in the neocortex: mechanisms underlying recovery from early brain damage. Prog Neurobiol 1989;32:235-276

3. Finger S, Wolf $\mathrm{C}$. The "Kennard effect" before Kennard: the early history of age and brain lesions. Arch Neurol 1988;45: 1136-1142

4. Krynauw RA. Infantile hemiplegia treated by removing one cerebral hemisphere. J Neurol Neurosurg Psychiatry 1950;13: 243-267

5. Verity CM, Strauss EH, Moyes PD, et al. Long-term follow-up after cerebral hemispherectomy: neurophysiologic, radiologic, and psychological findings. Neurology 1982;32:629-639

6. Chugani HT, Shields WD, Shewmon DA, et al. Infantile spasms: I. PET identifies focal cortical dysgenesis in cryptogenic cases for surgical treatment. Ann Neurol 1990;27:406-413

7. Chugani HT, Shewmon DA, Shields WD, et al. Surgery for intractable infantile spasms: neuroimaging perspectives. Epilepsia 1993;34:764-771

8. Day PS, Ulatowska HK. Perceptual, cognitive, and linguistic development after early hemispherectomy: two case studies. Brain Lang 1979;7:17-33

9. Vargha-Khadem F, Isaacs EB, Papaleloudi, et al. Development of language in six hemispherectomized patients. Brain 1991; 114:473-495

10. Ptito A, Lassonde M, Lepore F, Ptito M. Visual discrimination in hemispherectomized patients. Neuropsychologia 1987;25: 869-879

11. Chugani HT, Phelps ME. Maturational changes in cerebral function in infants determined by ${ }^{18} \mathrm{FDG}$ positron emission tomography. Science 1986;231:840-843

12. Chugani HT, Phelps ME, Mazziotta JC. Positron emission tomography study of human brain functional development. Ann Neurol 1987;22:487-497

13. Rintahaka PJ, Chugani HT, Messa C, et al. Hemimegalencephaly: evaluation with positron emission tomography. Pediatr Neurol 1993;9:21-28

14. Leonard CT, Goldberger ME. Consequences of damage to the sensorimotor cortex in neonatal and adult cats. I. Sparing and recovery of function. Dev Brain Res 1987;32:1-14

15. Villablanca JR, Gomez-Pinilla F. Novel crossed corticothalamic projections after neonatal cerebral hemispherectomy. Brain Res 1987;410:219-231

16. Hovda DA, Villablanca JR. Quantitative study of neural degeneration following neonatal or adult cerebral hemispherectomy in cats. Brain Dysfunct 1989;2:221-236

17. Hovda DA, Chugani HT, Villablanca JR. Lack of asymmetry in cerebral glucose metabolism in neonatal as compared to adult cerebral hemispherectomized cats. Soc Neurosci Abstr 1991;17: 894

18. Dauth GW, Gilman S, Frey KA, Penney JB Jr. Basal ganglia glucose utilization after recent precentral ablation in the monkey. Ann Neurol 1985;17:431-438

19. Goldman PS, Rosvold HE. The effects of selective caudate lesions in infant and juvenile thesus monkeys. Brain Res 1972;43: 53-66

20. Kling A, Tucker TJ. Effects of combined lesions of frontal granular cortex and caudate nucleus in the neonatal monkey. Brain Res 1967;6:428-439

21. McGeorge AJ, Faull RLM. The organization of the projection from the cerebral cortex to the striatum in the rat. Neuroscience 1989;29:503-537

22. Kolb B, Gibb R, van der Kooy D. Cortical and striatal structure and connectivity are altered by neonatal hemidecortication in rats. J Comp Neurol 1992;322:311-324
23. Whishaw IQ, Kolb B. Sparing of skilled forelimb reaching and corticospinal projections after neonatal motor cortex removal or hemidecortication in the rat: support for the Kennard doctrine. Brain Res 1988;451:97-114

24. Goldman PS. Contralateral projections to the dorsal thalamus from frontal association cortex in the rhesus monkey. Brain Res 1979;166:166-171

25. Sharp FR, Evans KL. Bilateral $\left[{ }^{14} \mathrm{C}\right] 2$-deoxyglucose uptake by motor pathways after unilateral neonatal cortex lesions in the rat. Dev Brain Res 1983;6:1-11

\section{Apolipoprotein E $\varepsilon 4$ Allele Distribution in Alcoholic Dementia and in Alzheimer's Disease in Japan}

Taro Muramatsu, MD, ${ }^{*}$ Susumu Higuchi, MD, PhD, ${ }^{*}$ Hiroyuki Arai, MD, PhD, $†$ Hiderada Sasaki, MD, PhD, $\uparrow$ Koichi Yamada, MD, ${ }^{*}$ Motoi Hayashida, MD, ScD, ${ }^{*}$ and John Q. Trojanowski, MD, PhDł

The apolipoprotein $\mathrm{E} \varepsilon 4$ allele has been associated with both familial and sporadic Alzheimer's disease (AD). Given its possible role in nerve repair and growth, it is plausible that apolipoprotein $\mathrm{E}$ may be a common denominator in the pathogenesis of several dementing diseases. Therefore, we investigated $\varepsilon 4$ frequencies in demented and nondemented alcoholics, as well as in patients with sporadic $\mathrm{AD}$ and controls in Japan. No significant difference in allele frequencies was found between demented and nondemented alcoholics and controls, while a significant association was demonstrated between $\mathrm{AD}$ and the $\varepsilon 4$ allele. These results support a specific role of $\varepsilon 4$ in the pathogenesis of $A D$, rather than a more general role for $\varepsilon 4$ in dementing illnesses.

Muramatsu T, Higuchi S, Arai $\mathrm{H}$, Sasaki $\mathrm{H}$, Yamada K, Hayashida M, Trojanowski JQ. Apolipoprotein $\mathrm{E} \varepsilon 4$ allele distribution in alcoholic dementia and in Alzheimer's disease in Japan. Ann Neurol 1994;36:797-799

Since the first report by Strittmatter and colleagues $\{1\}$, there have been several additional studies that have demonstrated an association between the apolipopro-

From the ${ }^{*}$ National Institute on Alcoholism, Kurihama National Hospital, Yokosuka, Kanagawa, and †Department of Geriatric Medicine, Tohoku University School of Medicine, Sendai, Japan; and $¥$ Department of Pathology and Laboratory Medicine, University of Pennsylvania School of Medicine, Philadelphia, PA.

Received May 18, 1994. Accepted for publication Jun 9, 1994.

Address correspondence to Dr Muramatsu, National Institute on Alcoholism, 5-3-1 Nobi, Yokosuka, Kanagawa 239, Japan. 